\title{
From a traditional steel producer towards an industrial product-service systems provider in the German offshore wind market - a system-oriented practical case study
}

\section{Evgenija Ries*, Lisa Grandjean and Marion Steven}

\author{
Chair of Production Management \\ Ruhr-University of Bochum, \\ Universitätsstraße 150, 44801 \\ Bochum, Germany \\ Email: evgenija.ries@rub.de \\ Email: lisa.grandjean@rub.de \\ Email: marion.steven@rub.de \\ *Corresponding author
}

\begin{abstract}
Globalisation and overcapacities lead to increasing competition within the steel market. Hence, steel producers are forced to enter promising markets like the offshore wind market. Moreover, they have to offer innovative products like industrial product-service systems $\left(\right.$ IPS $\left.^{2}\right)$. Both entering the offshore wind market and offering IPS $^{2}$ are challenging (each aspect per se is ambitious and above all the combination) since these two aspects demand for a shift of the steel producer's existing business model. Especially, the adaption of the key resources within the business model is challenging. In particular, the steel producer needs to acquire new competencies. Against this background, there is an urgent need for an integrative analysis of the decision-making problem concerning the acquisition of these competencies. For this purpose, the system-oriented and holistic approach of system dynamics is used within a practical case study.
\end{abstract}

Keywords: steel producers; steel market; German offshore wind market; new markets; industrial product-service systems; holistic solutions; business models; business strategy; requirement of competencies; system dynamics approach; practical case study.

Reference to this paper should be made as follows: Ries, E., Grandjean, L. and Steven, M. (2017) 'From a traditional steel producer towards an industrial product-service systems provider in the German offshore wind market - a system-oriented practical case study', Int. J. Markets and Business Systems, Vol. 3, No. 1, pp.18-38.

Biographical notes: Evgenija Ries is a Master of Science in Management and Economics and a Research Assistant at the Chair of Production Management at the Ruhr-University of Bochum, Germany.

Lisa Grandjean is a Master of Science in Management and a Research Assistant at the Chair of Production Management at the Ruhr-University in Bochum, Germany. 


\begin{abstract}
Marion Steven is a Professor and holds the Chair of Production Management at the Ruhr-University Bochum, Germany. She is also a member of the Board of Directors of the Institute of Management (ifu) at the Ruhr-University Bochum. Further, she was the Deputy Speaker of the German Science Foundation (DFG) Founded Project SFB/TR 29 on Industrial Product-Service-Systems from 2013-2015. Her current research focuses on industrial product-service systems, Industry 4.0 , production theory and sustainability management.
\end{abstract}

\title{
1 Introduction
}

In the last decade, the competition situation among steel producing companies has changed. Existing overcapacities cause an excess supply of steel products and globalised markets lead to increasing competition especially with steel producing companies from countries with location-specific low costs (Commitment for Steel, 2016; Ries, 2016).

Against this background, many steel producers try to enter emerging markets to reduce the overcapacities. The offshore wind market is a worldwide emerging and, therefore, new market. Moreover, this market has a high demand for steel structures, which are necessary for the construction of offshore wind power plants. For this reason, many steel producers try to enter the offshore wind market by offering steel structures.

Furthermore, especially steel producers with location-specific high costs need to offer products, which allow a competitive differentiation from competitors with location specific low-cost advantages (Porter, 1998). In this regard, industrial product-service systems (IPS ${ }^{2}$ ) provide an opportunity for competitive differentiation (Mont, 2002; Meier et al., 2010a). IPS ${ }^{2}$ are individually tailored problem solutions, which encompass carefully matched products and related services. This increased service orientation among traditional manufacturers is also referred to as servitisation (Vandermerwe and Rada, 1988). Because of its holistic nature, IPS ${ }^{2}$ provide a certain value added to the customer (Baines et al., 2007). Offering IPS ${ }^{2}$ means selling functionality instead of selling physical products (Meier et al., 2010a). Therefore, offering IPS $^{2}$ leads to a shift of the company's underlying business logic, which is captured in its business model (Baines et al., 2009; Osterwalder and Pigneur, 2010). Hence, entering the offshore wind market by offering IPS $^{2}$ requires a change of the steel producers hitherto business model (Meier et al., 2010a; Kindström, 2010).

However, current research gives little support regarding the business model innovation from a provider of physical products towards an IPS $^{2}$ provider (Oliva and Kallenberg, 2003; Wallin et al., 2013). In particular, literature concerning business models primarily concentrates on defining and categorising business models. However, little research focuses on operationalising business models for enhanced decision support (Täuscher and Chafac, 2016). Besides that, there is no support regarding the acquisition of the required competencies taking into account the special characteristics of the offshore wind market. So far, there is no integrative analysis, which includes all of these aspects.

However, current research gives little support regarding the business model innovation from a provider of physical products towards an IPS $^{2}$ provider (Oliva and Kallenberg, 2003; Wallin et al., 2013). In particular, literature concerning business models primarily concentrates on defining and categorising business models. However, 
little research focuses on operationalising business models for enhanced decision support (Täuscher and Chafac, 2016). Besides that, there is no support regarding the acquisition of the required competencies taking into account the special characteristics of the offshore wind market. So far, there is no integrative analysis, which includes all of these aspects.

1 Either the competencies are developed by provisioning trainings for the company's personnel (internal development).

2 By cooperating with a strategic partner, who already has the required competencies (external development).

These two options imply different effects on the possible production volume of the IPS ${ }^{2}$ provider. These effects have to be considered carefully and holistically. Therefore, the decision-making problem will be described and analysed by using the system oriented approach of system dynamics.

\section{Theoretical background}

\subsection{IPS $^{2}$ business models}

The holistic change of value creation within IPS ${ }^{2}$ in comparison to traditional physical products requires an appropriate understanding of innovative IPS $^{2}$ business models. In this context, it is important to characterise IPS ${ }^{2}$ itself. IPS ${ }^{2}$ are holistic and customised problem solutions including product and service components, (Baines et al., 2007) in business-to-business applications (Meier and Kortmann, 2007). The planning, development, provision, and use of product and service components within an IPS ${ }^{2}$ occur systematically and are mutually interdependent (Meier et al., 2010a). In addition, IPS ${ }^{2}$ are characterised by a multi-annual lifecycle that leads to long-term business relationships. In order to fulfil the customer's individual needs constantly, IPS $^{2}$ have to be adapted if the requirements change. Hence, IPS $^{2}$ need to be dynamically effective (Grandjean et al., 2014).

Although there are many studies concerning business models in general (Amit and Zott, 2001; Teece, 2010), little research concentrates on the specifics of IPS ${ }^{2}$ business models (Wallin et al., 2013). According to Osterwalder and Pigneur (2010), a business model is defined as a holistic, but simplified description of a company's value creation. An IPS ${ }^{2}$ business model captures the concrete features of an IPS ${ }^{2}$, e.g., the configuration of the products and services provided (Meier et al., 2010b; Meier and Bosslau, 2013). Since each IPS $^{2}$ is an individual solution for a certain customer, it is mostly unique (Meier et al., 2010a, Grandjean et al., 2014). Hence, an IPS ${ }^{2}$ business model characterises the individual relationship of an IPS $^{2}$ provider with a certain customer (Meier et al., 2010b; Meier and Bosslau, 2013; Rese et al., 2013). Third-party value-adding partners are also involved (Meier et al., 2010b; Zott and Amit, 2010; Meier and Bosslau, 2013). To reduce complexity, business models are subdivided into interrelated partial models. Analysing one certain partial model is often beneficial for the understanding of certain issues and situations (Osterwalder and Pigneur, 2010). As illustrated in Figure 1, an IPS ${ }^{2}$ business model is structured into nine interrelated partial models (Wallin et al., 2013; Grandjean et al., 2017). 
For becoming an IPS ${ }^{2}$ provider in the offshore wind market, all partial models of the steel producer's previous business model need to be modified (Kindström, 2010). Due to the servitisation the partial model key resources needs to be adapted substantially. As can be seen in Figure 1, the partial model key resource includes tangible resources (like buildings), financial resources (like lines of credit) and intangible resources (Lev, 2001; Osterwalder and Pigneur, 2010). Intangible resources contribute to the firm's value, but do not have a tangible or financial embodiment (Lev, 2001; Wewior et al., 2014). If intangible resources are legally protected, they are referred as intellectual property (Lev, 2001). For becoming an IPS $^{2}$ provider, intangible resources are crucial (Wewior et al., 2014). Intangibles consist of three groups: structural capital, e.g., communication systems, relational capital, e.g., relations to suppliers, and human capital, e.g., competencies (Teece, 2000).

Figure 1 IPS $^{2}$ business models and competencies

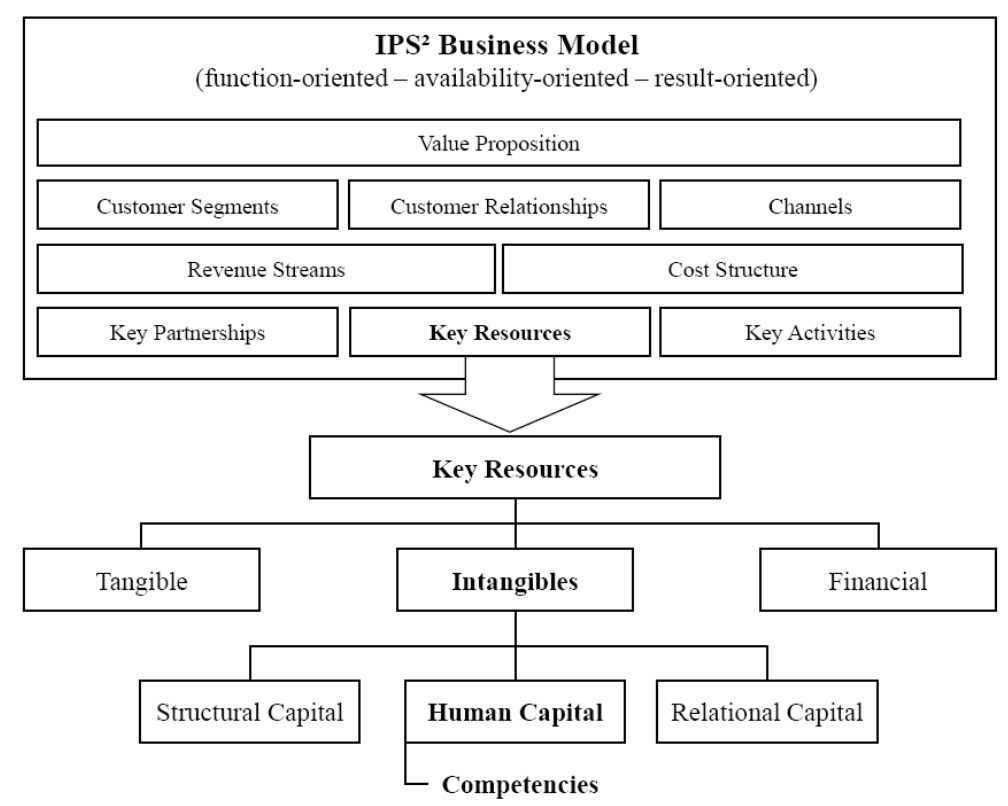

The IPS ${ }^{2}$ business model describes the concrete configuration of attributes of partial models for a specific customer (Meier et al., 2010b; Meier and Bosslau, 2013). Each partial model centres on answering one of the following questions (Osterwalder and Pigneur, 2010):

- Value proposition (Which value added does the offer provide to the company's customers?)

- Customer segments (Who is the target group?)

- Channels (How does the company reach its customers?)

- Customer relationships (What kind of relationship do the customers expect?) 
- Key partnerships (Which partners does the company need to fulfil the value proposition?)

- Revenue streams (What are the customers willing to pay for?)

- Cost structure (What are the most important costs?)

- Key activities (Which activities are necessary to fulfil the value proposition?)

- Key resources (Which resources are necessary to fulfil the value proposition?).

For a deeper understanding of the importance of the partial model key resources and its different specifications, three types of IPS ${ }^{2}$ business models are considered, namely a function-oriented, an availability-oriented and a result-oriented IPS ${ }^{2}$ business model (Meier et al., 2010a; Steven et al., 2011). These types are roughly illustrated by using the partial models value proposition and key resources (Meier et al., 2010a; Steven et al., 2011; Grandjean et al., 2017). Although the focus is on the key resources, the value proposition is also considered, since the latter significantly determines the key resources, which are required.

- In the function-oriented business model, the IPS ${ }^{2}$ provider guarantees the functionality of a facility by offering physical products and related services for an agreed period of time (value proposition). Hence, the focus lies primarily on the physical core product and therefore, on tangible resources (key resources).

- An availability-oriented business model also guarantees the usability (value proposition). Accordingly, the core product and the related services and thus, tangible and intangible resources are approximately equally important (key resources).

- In a result-oriented business model, the IPS ${ }^{2}$ provider assumes responsibility for the entire production processes (value proposition). Here, the IPS ${ }^{2}$ provider has to perform a wide range of services. In this case, the focus lies on the intangible resources (key resources).

\subsection{Competencies within the scope of IPS ${ }^{2}$ and the offshore wind market}

In the present practical case study, the focus lies on the competencies, which a traditional steel producer needs to enter a new and emerging market by offering an IPS ${ }^{2}$. Competencies play a significant role in the context of IPS $^{2}$ business models in the offshore wind market for two reasons. Firstly, new competencies are needed because of the specific characteristics of the offshore wind market. Since this market is still young, many technologies, methods and tools need to be adapted. Secondly, the personnel of a formerly product-oriented business model need new competencies, when switching towards an IPS $^{2}$ business model (Windahl et al., 2004; Storbacka, 2011; Kurak et al., 2013). Managerial and technical methods, tools, and processes focusing on providing physical products need to be adapted for an efficient use in case of IPS ${ }^{2}$ (Johansson et al., 2003; Steven and Soth, 2010; Grandjean et al., 2014).

Competencies include abilities, knowledge, experiences and skills for acting effectively in various situations and generate new approaches to solve problems (Mänz et al., 2013). Further, competencies involve that a company uses its resources efficiently 
and effectively in accordance to its objectives and thereby to generate value. The participating parties of the IPS ${ }^{2}$ value creation need to understand the complex technical systems and included services (Meier et al., 2010a). Additionally, the generation of innovative and customer-specific solutions is requested (Meier et al., 2010a; Steven and Soth, 2010). As a result, complexity and the need for coordination within the own organisation and with networking partners rises (Wewior et al., 2014). In order to cope with these high requirements of work, there is a need for professional and interdisciplinary competencies, e.g., combination, cooperation and self-reflection (Mänz et al., 2013; Externbrink et al., 2013).

Comparable to other key resources, there are two ways to obtain the competencies required: either an internal development via trainings of the personnel or an external development via a strategic merger with a partner (Osterwalder and Pigneur, 2010). For choosing the right option, an in-depth analysis considering the specific features of the German offshore wind market is performed.

\section{System dynamics}

\subsection{Approach}

The approach of system dynamics was introduced by J. Forrester in the late 1950s (Forrester, 1958). Essentially, the core of the system dynamics approach is based on the theory of System Thinking, which can be understood as a discipline used for understanding and analysing situations and problems in a holistic context (Richmond, 1993). The discipline of systems thinking is needed, because of the assumption, that humans draw incorrect conclusions and hence make erroneous decisions due to limited perception of the human mind and imperfect information (Richmond, 2013). Systems thinking principles like focusing on causal relationships and feedback loops provide a deeper and holistic understanding of a decision-making problem (Banson, 2015; Täuscher and Chafac, 2016).

Figure 2 System dynamics approach - procedure

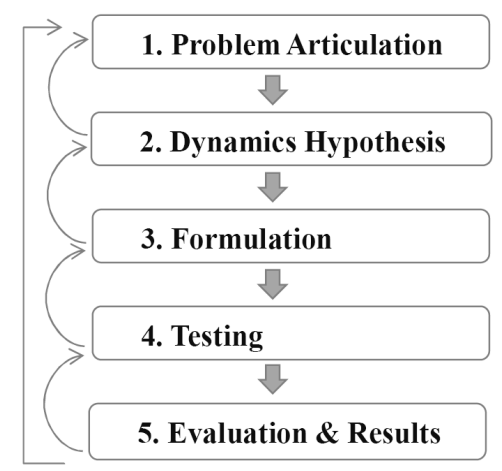

System dynamics is a quantitative and experimental approach, which provides a basis for the design and understanding of effective economic and industrial systems (Forrester, 1958; Morecroft, 2015). 
The procedure of the system dynamics approach can be broken down into five steps (see Figure 2). Logically separated tasks can be assigned to each step (Sterman, 2000; Morecroft, 2015).

The first step problem articulation comprises the description of the decision-making problem, which shall be answered using the system dynamics approach. For this step, the principles of systems thinking are particularly essential, since a systematic and holistic contemplation is related with the success of the system dynamics approach. In this step, the boundaries of the considered problem shall be defined, which then can be seen as the boundaries of the considered system. The aim is to identify the essential elements and set a reasonable time horizon, which is necessary to analyse the problem within the system (Sterman, 2000; Morecroft, 2015).

In the second step dynamic hypothesis, the formulation of the system follows. For this step it is crucial to capture the problem's structure and behaviour in a system oriented as well as in a time-oriented, therefore, dynamic way. The core of this step is the identification and representation of causal relationships within the previously defined system. The causal relationship between at least two considered elements is represented by a positive or negative link. If elements are in a positive causal relationship, then they are connected by a positive link. Referring to Figure 3 this means that the numerical value of element $X$ (cause) and the numerical value of element $Y$ (effect) move in the same direction. In other words, an increase (respectively decrease) of element $\mathrm{X}$ leads to an increase (respectively decrease) of element $Y$.

In a negative causal relationship, an increase (respectively decrease) of element $\mathrm{X}$ (cause) leads to a decrease (respectively an increase) of element Y (effect).

Figure 3 Causal relationships
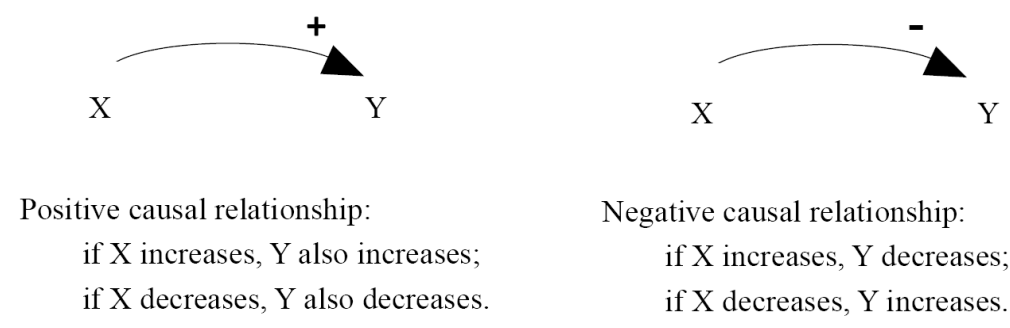
Negative causal relationship:
if $\mathrm{X}$ increases, $\mathrm{Y}$ decreases;
if $\mathrm{X}$ decreases, $\mathrm{Y}$ increases.

Usually a feedback loop consists of several elements respectively several causal relationships. Analogously, feedback loops can be either positive or negative. In a positive feedback loop, also called reinforcing loop, the change of condition (e.g., increase of element $\mathrm{X}$ ) is amplified. In a negative loop, called balancing loop, a change of condition is not reinforced through the loop, but absorbed, and therefore balanced, by one or several elements within the loop (Morecroft, 2015). Several interconnected feedback loops form a causal-loop diagram. These causal-loop diagrams can be transferred into Stock-and-Flow diagrams. Stock-and-flow diagrams in comparison to causal-loop diagrams differentiate between stocks and flows. Stocks are physical or immaterial accumulations, which characterise the stage of a considered system at every point. Flows represent the dynamics of a system; they alter the stock by inflow or outflow (Sterman, 2000; Morecroft, 2015). 
After the first two rather qualitative steps, a quantitative step called formulation follows. This step comprises the mathematical formulation of causal-loop diagrams, respectively, Stock-and-flow diagrams. Through the draw up of mathematical equations and functions a simulation model is developed.

In the subsequent step testing, the mathematical formulations, thus the simulation, are tested by, e.g., structural tests or behavioural tests for verification and validation.

In the last step evaluation and results, the results of the simulation are analysed and evaluated. So, decisions can be derived according to the considered problem (Barlas, 1996; Morecroft, 2015).

Since the System Dynamics approach follows an iterative construction, it is possible to return from one step to another and thus adapt each step according to new findings or change according to new assumptions (Sterman, 2000).

\subsection{Decision support by using system dynamics}

Decision makers face difficulties in drawing correct decisions, e.g., due to the limited perception of human mind, especially in complex and dynamic situations. Without suitable tools there is hardly any chance for the decision maker to make an appropriate decision. For making a well-founded decision, the understanding of the structure as well as the time depended behaviour within the decision situation is indispensable. In that regard, recent literature refers to the system dynamic approach as a tool, which enables a deeper understanding of structure and behaviour of dynamic systems and therefore solving sophisticated problems (Morecroft, 2015). This is especially necessary in case of a business model innovation caused by entering new markets and offering innovative products.

By using the system dynamics approach a holistic view by inter alia identification of cause-and-effect (causal) relationships and feedbacks within the decision situation is encouraged. In addition, the systematic approach of system dynamics (see Figure 2) provides a universal frame, which enables to structure and capture even supposed vague and multivariable decision situations.

Due to the possibility of repeating a system dynamics simulation with various alternatives, an appropriate understanding is promoted. System dynamics enhances an indepth understanding of the structure of the relevant elements as well as their interactions within the decision-making problem. Thus, the system dynamics approach is an essential basis for the decision-making process (Richmond, 2013).

Especially, in the last years the fundamental system-oriented understanding is revitalised in the field of business and managerial issues. This is due to "the social and economic complexity of our times" and the accompanying need of a "paradigm shift from the analytical reductionist approach, and towards a more comprehensive systemic perspective" [Dominici (2012), p.1]. In recent literature, the system dynamics approach is used for various purposes in business managerial contexts. Such as understanding the structure and behaviour of a whole market as well as for understanding and analysing different business strategies (Banson, 2015; Nguyen et al., 2015; Torres et al., 2017). Further, System Dynamics is used for analysing decision-making problems concerning the adaption of partial models within business models in manifold contexts (Maani, 2004; Meier and Bosslau, 2013; Abdelkafi and Täuscher, 2016; Täuscher and Chafac, 2016). 


\section{Practical case study from the German offshore wind market}

\subsection{Background}

The case study presented is based on collaboration with a North European steel producer. As mentioned before, this steel producer faces the major challenges of global excess of steel products and increasing cost pressure from competitors from 'low-cost'-countries. To overcome these challenges, the steel producer intends to enter the offshore wind market in the German North Sea, which is a new and emerging market (reduction of the steel product excess) by offering an IPS $^{2}$ (competitive differentiation from 'low-cost'-competitors). From the steel producer's perspective entering a new market in combination with offering IPS $^{2}$ requires substantial changes in its business model, especially concerning the acquisition of new competencies.

Before pointing out the research issue in the present context and illustrating the implementation of the system dynamics approach according the research issue, there will be a very brief introduction of the German offshore wind market.

Basically, the offshore wind market is characterised by the prime objective of generating electrical power through offshore wind parks, which means harvesting wind energy at the sea respectively in coastal areas. In general, an offshore wind park comprises several offshore wind power plants (see Figure 4). Offshore wind power plants within an offshore wind park are located closely to each other as well as similar according their physical specifications. Generally, an offshore wind power plant consists of a turbine, a turbine tower and a foundation. The tower holds the turbine. The foundation is anchored into the seabed and holds the tower and the turbine (Kaiser and Snyder, 2012; Thomsen, 2014).

Figure 4 Generic offshore wind power plant (see online version for colours)

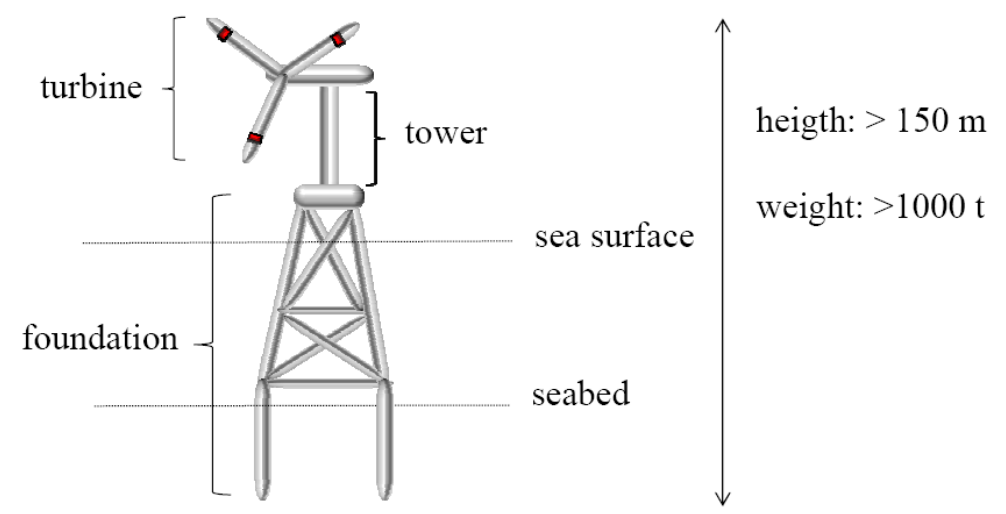

In the last years the offshore wind market at the German North Sea became one of the largest offshore markets worldwide. Nevertheless, this market is still at the beginning of industrial development and characterised by many uncertainties in various fields. At the same time, this market also holds a high potential for many stakeholders. Due to the market's high demand for steel, this especially applies for steel producers. The majority of planned offshore wind parks within the German North Sea are currently in the governmental approval process. It is assumed, that in the next 10-15 years more than 
6,600 offshore wind power plants will be erected (Federal Ministry for Economic Affairs and Energy, 2015; Foundation Offshore Wind Energy, 2016).

Typically, multi-contracting is the dominant contracting in the German offshore market. This means, that the erection of a whole offshore wind park is not done by only one contractor. Because of the wide scope of required competencies and responsibilities, uncertainties and therefore risks can hardly be borne by solely one contractor. That is the reason why the owner of an offshore wind park hires specified suppliers for the manufacturing and installation of each (main) component of an offshore wind power plant (Kaiser and Snyder, 2012).

In the context of the case study, the considered steel producer intends to enter the offshore market in a function as a specified supplier. As mentioned before, providing an IPS $^{2}$ means solving a customer's problem. Here, the considered steel producer intends to solve the customer's problem, which consists of erecting an offshore wind park. More precisely, the steel producer provides the manufacturing and installation of a specific component of an offshore wind power plant, namely the steel foundation. That is why the intended IPS ${ }^{2}$ consists of a steel foundation (core product) and the corresponding installation (service part). Therefore, the steel producer offers the IPS ${ }^{2}$ in a result-oriented business model.

The present case study focuses on the acquisition of the competencies for the installation of the foundation of the offshore wind power plant. This will be discussed by using the system dynamics approach and taking into account the main characteristics in the regarded context of IPS $^{2}$ as well as the business environment within the German North Sea.

\subsection{Step 1: problem articulation}

Now for the steel producer the question arises of how to acquire the competencies. The considered steel producer has competencies regarding the production and the manufacturing of the steel foundation (core product). But he has a lack of competencies that are needed for the installation of the steel foundation in the seabed. Due to the fact that maritime services like underwater installations are no core competencies of traditional steel producers, those competencies need to be acquired. For this purpose, two distinctive options of competencies acquisition exist:

- Option A (company's internal development) is an internal development of competencies required, e.g., training company's personnel.

- Option B (merger with a strategic partner) is an external development of competencies required by a merger with a strategic partner, who has the required competencies.

The comparison of these options is based on the possible production volume (decision-making variable). On a strategic level the possible production outcome is easier to investigate than the estimated costs, since there are almost no experiences of the costs for the steel producers with regard to the offshore wind market. In the present context the possible production volume corresponds to the amount of installed foundations of offshore wind power plants. In accordance to the lifecycle orientation of an IPS ${ }^{2}$, a period of ten years from now on is considered. This long-term period corresponds to the characteristics of an IPS $^{2}$. Furthermore, it is assumed that in this period major 
developments within the German North Sea offshore market will take place. The focus of the next considerations and thus the dynamic hypotheses will be on the installation process, since this is the required competency from the perspective of the steel producers. So, the production and manufacturing of the steel foundation is not in the scope at this point, because it can be assumed that the steel producer already possesses competencies of the processes related to the production and manufacturing. Besides that, those processes are identical in the considered options.

\subsection{Step 2: dynamic hypothesis}

For the present decision-making problem concerning the acquisition of the competencies, a comparison of the distinctive options A (company's internal development) and $\mathrm{B}$ (merger with a strategic partner) is needed. Therefore, an integrative analysis of the decision-making situation is performed. In a system-theoretical context, this primarily means identifying and understanding the feedbacks. Based on subject-specific studies and literature as well as discussions with experts, four main feedback loops are identified. In the following, these feedback loops will be described separately and then put together in a Causal-loop diagram, which captures the system-oriented structure of the underlying decision-making problem.

\subsubsection{Feedback loop 1 - characteristics of the German North Sea-distance}

The area of the German North Sea has a certain shape, which leads to decisive implications for its offshore market. The boundaries of the German North Sea are restricted by the marine areas of the Netherlands and Denmark. Hence, the shape of the German North Sea marine area is rather narrow, but in return extends relatively far away from the coast. At present the governmental approved and erected offshore wind parks are mainly located in coastal areas. The expansion of the market develops gradually from the near coastal areas, which are located some nautical miles away from the shore, to far offshore areas, which can be more than 200 nautical miles away from the coast (Federal Ministry for Economic Affairs and Energy, 2015). This leads to several causal relationships, which are illustrated in Figure 5.

Figure 5 Characteristics of the German North Sea - distance $\left(B_{1}\right)$ (see online version for colours)

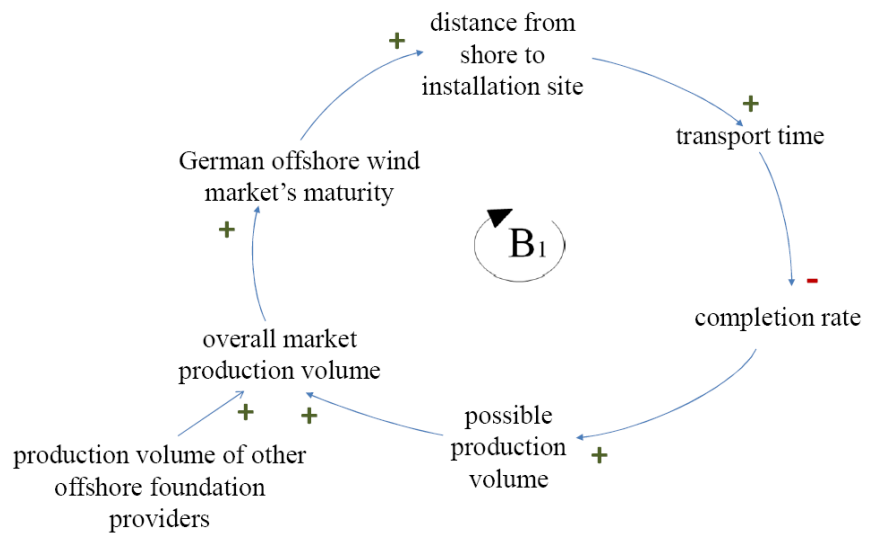


An increase of installed foundations respectively offshore wind power plants (overall market production volume) enhances the market's development, and therefore, leads to an increase of the maturity of the German offshore wind market (German offshore wind market's maturity).

Due to the specific shape of the German offshore marine area, the offshore wind market develops gradually from shore into the far sea. The more the market matures; the distance from the shore to the remaining installation sites enlarges. For this reason, an increase of the market's maturity leads also to an increase in the distance, which is has to be overcome to reach the particular installation site (distance from shore to installation site). Logically, there is a positive causal relationship between the distance to the installation site and the time, which is needed to overcome that distance (transport time).

For any process which is done offshore respectively at an offshore installation site, the necessary personnel and any kind of material need to be transported from shore to the particular site (Kaiser and Snyder, 2012; Thomsen, 2014). That is why, an increase of the transport time leads to an increase of the whole completion time. The completion time is the time-span, which is needed to complete the foundation. It is important to point out, that an increase in the completion time leads to a decrease in the completion rate. The completion rate represents how many foundations can be completed in a certain period, e.g., two foundations/day, which means the completion time for one foundation equals one half of a day. Therefore, there is a negative causal relationship between the transport time and the completion rate. Obviously, the completion rate has a positive causal relationship to the amount of installed foundations and hence, to the possible production volume (see 4.1).

Further, an increase of the possible production volume of one provider as well as the production volume of his competitors (production volume of other offshore foundation providers) leads to an increase of the overall market production volume, which again leads to an increase of the maturity of the entire market (German offshore wind market's maturity). In this way, the described causal relationships form a feedback loop.

Because of the odd number of negative causal relationships within the loop (negative causal relationship between transport time and completion rate), this feedback loop is a balanced feedback loop $\left(\mathrm{B}_{1}\right)$ (Sterman, 2000).

\subsubsection{Feedback loop 2 - characteristics of the German North Sea-water depth}

Increasing distance from the shore does not only effect the transport time, as mentioned before (see feedback loop 1), but also the water depth. This can be seen in Figure 6. With increasing distance from shore the water depth increases, because the seabed slopes gradually away from the shore (ca. $15 \mathrm{~m}$ depth) into the northern part of the Atlantic Ocean. At the farthest edge of the German North Sea area the water depth is more than 55 m (Federal Ministry for Economic Affairs and Energy, 2015; Foundation Offshore Wind Energy, 2016).

Generally, all processes, which are related to offshore underwater installation, have a certain degree of difficulty. This degree is growing with increasing water depth. This also results in increasing technical requirements due to, e.g., poor underwater visibility and strong underwater currents (underwater flows) (Kaiser and Snyder, 2012; Thomsen, 2014). 
Figure 6 Characteristics of the German North Sea - water depth $\left(\mathrm{B}_{2}\right)($ see online version for colours)

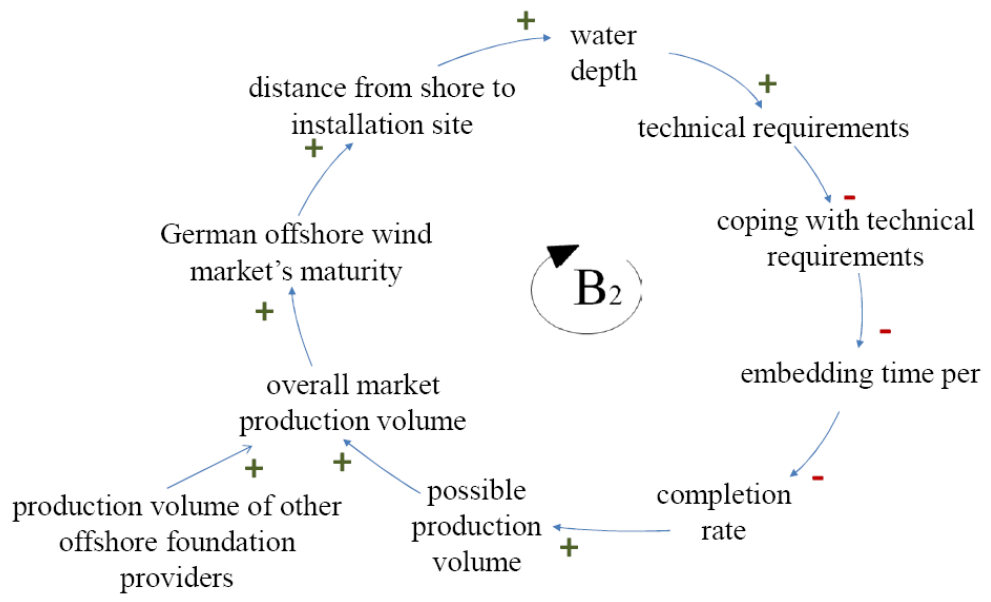

If technical requirements increase, then the ability to cope with them (coping with technical requirements) decreases as long as there are no learning effects or other measures, which could increase the available ability. However, the ability of coping with technical requirements affects the process of embedding the foundation (e.g., by drilling, hammering or pushing) into the seabed. An increase of the ability leads to a decrease in the time, which is needed for the embedding of a foundation (embedding time per foundation), e.g., skilful handling of equipment.

Another negative causal relationship exists between the embedding time of a foundation into the seabed and the completion rate. Obviously, an increase of the embedding time per foundation leads to a decrease in the completion rate. The other causal relationships are the same as in feedback loop 1.

This feedback is characterised by an odd number of negative causal relationships within the loop and, therefore, corresponds to a balanced feedback loop $\left(\mathrm{B}_{2}\right)$.

\subsubsection{Feedback loop 3 - characteristics of IPS ${ }^{2}$ - learning}

Feedback loop 3 is shown in Figure 7 and mainly focuses on effects concerning the learning curve. First, there is a positive causal relationship between the completion rate and the possible production volume.

There is also a general causal connection between a company's production volume and the corresponding learning curve. Hence, the amount of processed production volume affects the learning curve in a causal positive way.

Human competencies within a company are affected to a great extent by the company's internal learning curve. If the learning curve increases, the human competencies increase (Lieberman, 1987; Bolivar-Ramos et al., 2012). So, there is a positive causal relationship. Further, an increase of the human competencies leads to an increase of ability of coping with technical requirements, which in turn lead to a decrease of the embedding time per foundation. The other causal relationships remain as describes above. 
Figure 7 Characteristics of IPS $^{2}-$ learning $\left(\mathrm{R}_{1}\right)$ (see online version for colours)

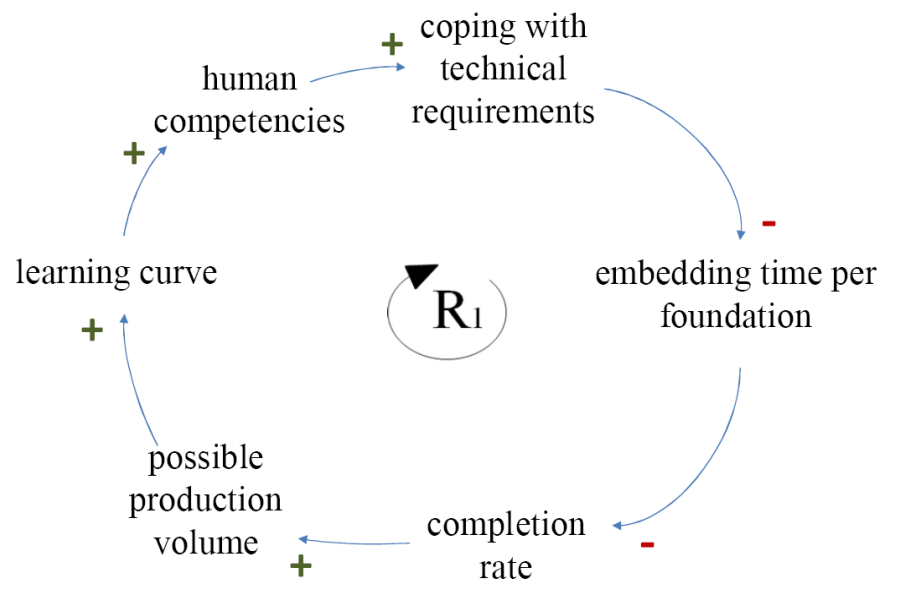

Since this feedback loop has an even number of negative causal relationships, the behaviour of this feedback loop is reinforcing $\left(\mathrm{R}_{1}\right)$.

\subsubsection{Feedback loop 4 - characteristics of IPS ${ }^{2}$ - individuality}

Figure 8 shows the fourth feedback loop. This last identified main feedback loop focuses on an aspect of IPS $^{2}$, which is essential in the context of the present decision. Each IPS ${ }^{2}$ is highly customer-specific and individual. Therefore, the competencies, which have been built up during the processing of one IPS ${ }^{2}$, are not completely transferable to another IPS $^{2}$.

In other words, an increase in the number of different IPS $^{2}$ also leads to an increase of the individual IPS $^{2}$ adjustment effort. The latter has a negative causal effect on the learning curve. (Note that an IPS $^{2}$ equals one customer specific order. Each order comprises several offshore wind power plant foundations.)

Figure 8 Characteristics of IPS ${ }^{2}$ - individuality $\left(B_{3}\right)$ (see online version for colours)
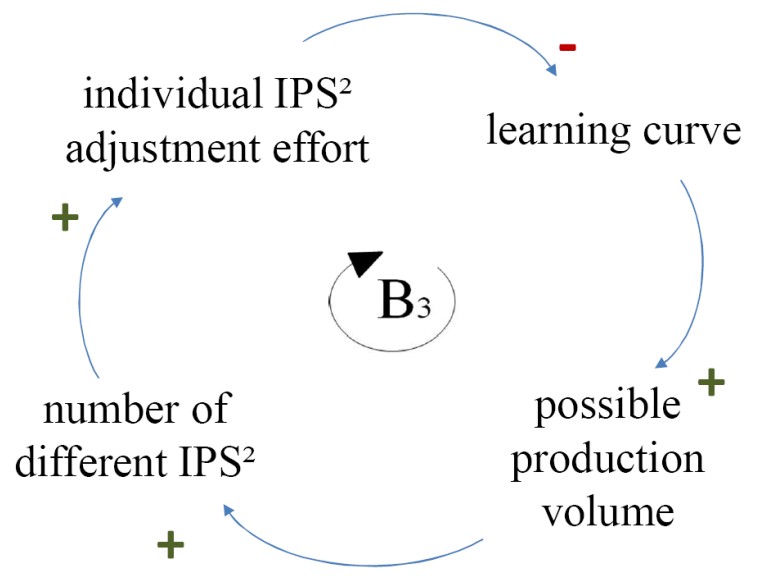
Furthermore, there is a positive causal relationship between the learning curve and the possible production volume. Finally, this feedback loop closes with the causal relationship between provider's possible production volume and the number of different IPS $^{2}$. An increase of the possible production volume consequently leads to an increase of the number of different processed IPS $^{2}$. To sum it all up, these causal relationships form a balanced feedback loop $\left(\mathrm{B}_{3}\right)$.

\subsubsection{Integrated causal-loop diagram}

In Figure 9 the main identified and described feedback loops are put together in one causal-loop diagram. This diagram represents the structure of the decision-making situation of the case study in a system-oriented way. Obviously, the identified feedback loops are not independent from each other.

Figure 9 Causal-loop diagram of the installation of the foundation (service part of the IPS ${ }^{2}$ )

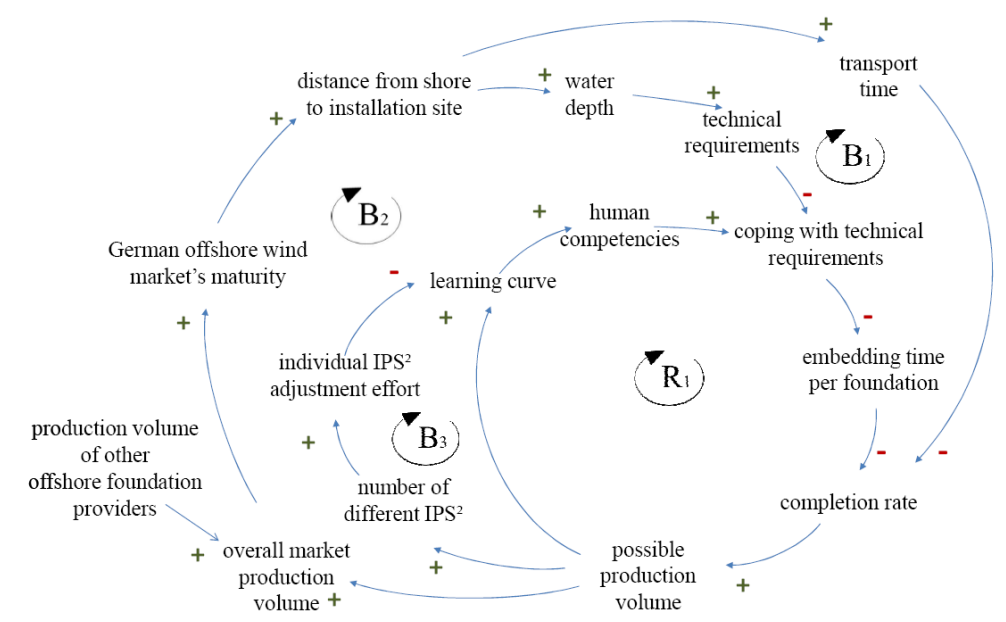

The intersections between the feedbacks loops within the Causal-loop diagram, like the feedback loop $\mathrm{B}_{2}$ (characteristics of the German North Sea - water depth) and feedback loop $\mathrm{R}_{1}$ (characteristics of IPS - learning) (through coping with technical requirements), are of particular interest, because these can have crucial and, therefore, decisive implications on the dominant behaviour within the decisions situation.

\subsection{Step 3: formulation}

At first, it is necessary to clarify the basic assumptions. It is assumed, that the IPS ${ }^{2}$ provider receives an order, which comprises the installation of 80 offshore wind power plant foundations. Every accepted order flows into an order backlog, which is a stock (Figure 10). As long as the order backlog is not fully processed, no other order will be accepted. Due to capacity restrictions, the IPS ${ }^{2}$ provider is not able to provide several orders simultaneously (Thomsen, 2014). Thus, the order intake rate, which flows into the order backlog, will be controlled by the auxiliary variable order rule. Due to the large 
potential of within the German North Sea offshore wind market, it can be assumed that as soon as the order backlog is processed, the next order comes in. The flow completion rate defines the rate with which the (foundations of the) order backlog is processed. Foundations are named processed foundations, if their installation in the seabed is completed. Thus, the processed foundations can be interpreted as the possible production volume. Therefore, the completion rate flows into the stock possible production volume.

Figure 10 Extended causal-loop diagram (see online version for colours)

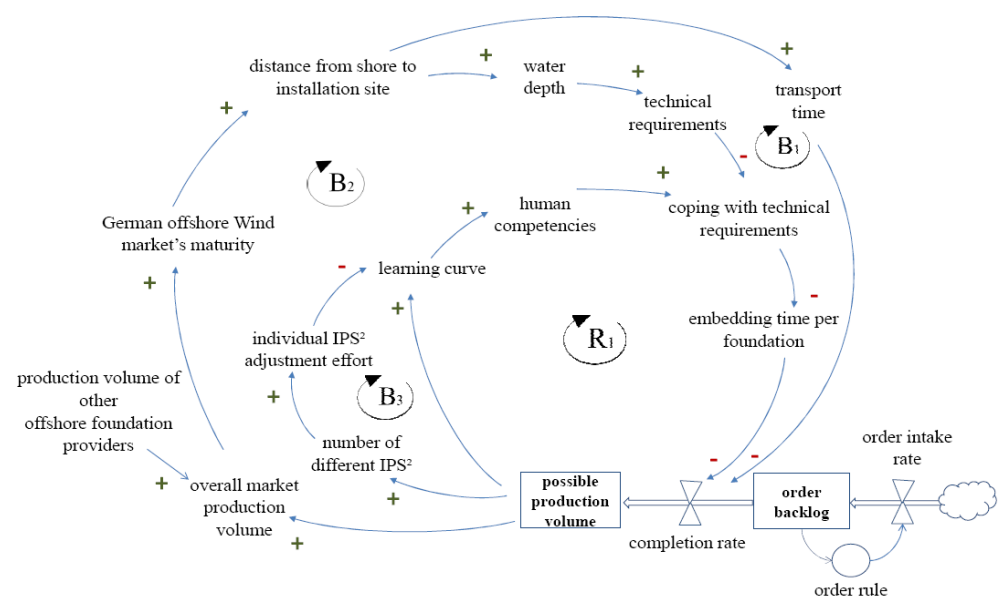

For establishing the simulation model, it is necessary to transfer the whole integrated Causal-loop diagram into a Stock-and-flow diagram. However, due to simplification solely the decision-making variable along with the assumptions explained according to the two options A and B, are shown in Figure 10 as stocks and flows. Thus, Figure 10 shows an aggregated level of the simulation model.

The mathematical formulations of the simulation model are based on data of the cooperating steel producer and discussions with experts as well as subject-specific studies and literature.

While the simulation model (all mathematical formulations) cannot be fully documented in this paper, the main assumptions towards the distinctive options A and B are highlighted, see Table 1.

Before entering the market, the development of competencies needs time (option A), but if those competencies are already required no time is needed (option B). Working with a strategic partner leads to a certain time before providing customer's order can be started with due to coordination and cooperation efforts (option B), without a company's external partnership such efforts and therefore such idle time can be omitted (option A).

The initial value of the completion rate is 0.1 foundation/day (ten days for one completed foundation). This initial value is identical for both options. The value of the effect from possible production volume on the effect on learning curve differs, due to the assumption that internal development of competencies has a higher degree of building up competencies among the company's personnel (option $A$ ) as external developed of those competencies (option B). 
Table 1 Assumption: values of the option A and option B

\begin{tabular}{lcc}
\hline & $\begin{array}{c}\text { Option A: company's } \\
\text { internal development }\end{array}$ & $\begin{array}{c}\text { Option B: merger with a } \\
\text { strategic partner }\end{array}$ \\
\hline Time for market entry & 700 (days) & 0 (days) \\
Idle time order intake & 0 (days) & 30 (days) \\
Initial value of completion rate & 0.1 (foundation/day) & 0.1 (foundation/day) \\
Effect on learning curve & 0.0005 (foundation/day) & 0.00025 (foundation/day) \\
\hline
\end{tabular}

The simulation of the flow completion rate has two forms. When the stock order backlog is zero and thus there are no intakes, then the flow completion rate is set to zero.

completion rate $=0$, if order backlog $=0$

If the stock order backlog has a positive value, then the flow Completion Rate is a function of its initial value as well as embedding time per foundation and transport time.

$$
\begin{aligned}
& \text { completion rate }=f \text { (initial value of completion rate, } \\
& \text { transport time, embedding time per foundation), } \\
& \text { if order backlog }>0
\end{aligned}
$$

Note that these variables are influenced by other variables; inter alia the learning curve, and the accompanying feedbacks within the decision-making situation (see Figure 10).

\subsection{Step 4: testing}

The considered simulation was checked by using two different tests for assessment of dynamic models. Firstly, an extreme-condition test and afterwards, a sensitivity-analysis test was carried out (Barlas, 1996; Sterman, 2000).

In the context of the extreme-condition test the unit consistency within the simulation was checked by inspections of equations within the simulation and by starting the simulation run. The simulation successfully passed both. Furthermore, the simulation was checked by choosing extreme values for several input variables. This was done to check if the simulation behaves in accordance to an expected pattern. The simulation also successfully passed this test. The focus of the sensitivity test was on numerical sensitivity (Sterman, 2000).

\subsection{Step 5: results and evaluation}

In the comparison option A (company's internal development) slightly dominates option B (merger with strategic partner), which means that the possible production volume of option A (463 foundations) over a time span of 10 years is exceeds the possible production volume of option B (441 foundations).

However, the sensitivity-analysis test shows that simulation experiments with moderate changes of the assumed (initial) value of the effect on the learning curve, in contrast to the time for market entry, idle time order intake and initial value of the completion rate (see Table 1) do alter the dominance among these options, but very slightly (464 foundations in comparison to 463 foundations in option A) (see Figure 11). 
Figure 11 Possible production volume - results (see online version for colours)

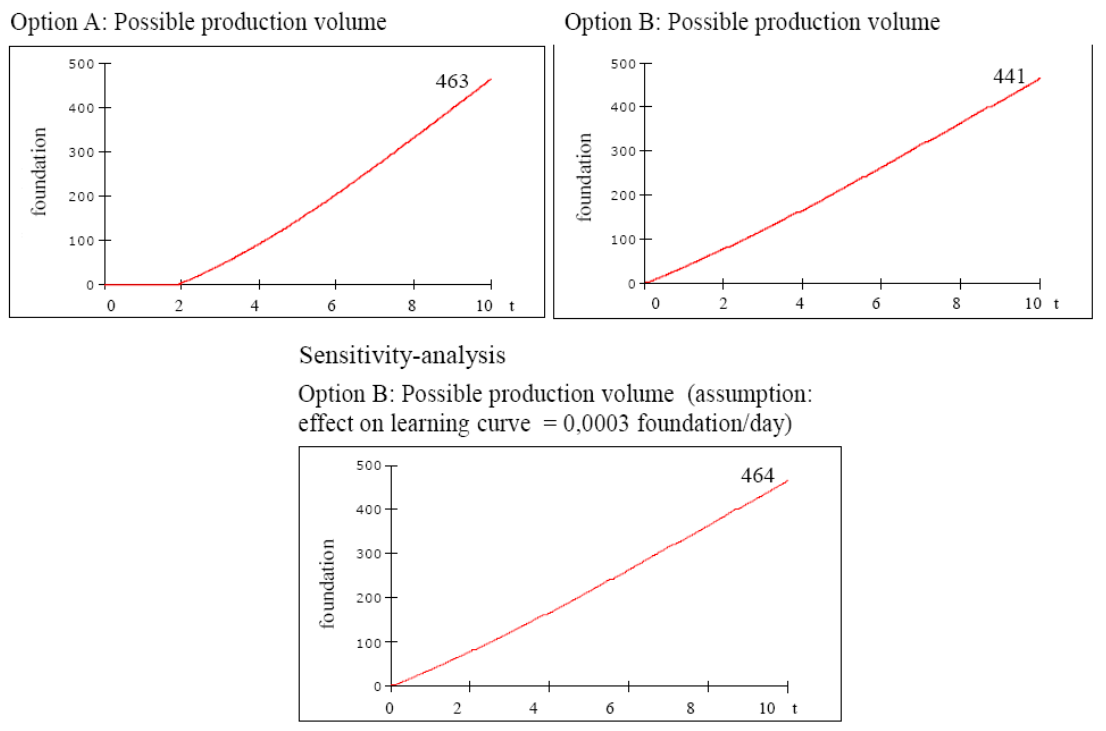

Therefore, it must be stated with reservation that building up competencies within the company is more advantageous than acquiring the required competencies from a strategic partnership in the practical case study.

\section{Conclusions and further steps}

For competitive reasons, steel producers enter new and emerging markets like the offshore wind market and expand their offerings by IPS ${ }^{2}$. The change of the company's business logic in case of offering IPS ${ }^{2}$ and the special characteristics of the offshore wind market necessitates the acquisition of new competencies. Particularly, the installation of the foundations in the seabed is noteworthy. Because of the new market and the integration of services new competencies are required.

Against this background, a practical case study is introduced. It describes a systematic examination of offering an IPS $^{2}$ within the German North Sea offshore wind market. The acquisition of the competencies is the centre of the integrative analysis. The case study's aim is to explore which of the two options (internal or external development of the required competencies) is more appropriate under the present considerations.

By using the system dynamics approach the causal relationships and the main feedback loops within the German North Sea offshore wind market and IPS ${ }^{2}$, focusing on competencies, were pointed out and put together into a causal-loop diagram.

Simulation experiments from a simulation model, which bases on this causal-loop diagram, show that option A (Company's internal development) is slightly dominant to option B (Merger with strategic partner) in the present case study. This result can be conformed also within the framework of the sensitivity-analysis, with one exception, where the dominance among the regarded alter, but in a vanishingly small manner. Furthermore, the structure of the Causal-loop diagram along with the its main feedback 
loops is generic in so far as the characteristics of the German North Sea offshore wind market and the characteristics of IPS ${ }^{2}$ are transferable.

Nevertheless, these findings are subject to limitation, because they are based on a company-specific case study. In further steps the simulation model has to be gradually extended with additional partial business models. Especially, the partial business models cost structure and revenue stream and the inherent interdependencies between the partial business models should be integrated in order to draw further conclusions and for a deeper understanding. In the context of this practical case study there is no consideration of uncertainty and flexibility. So, in a further step uncertainty and flexibility should be introduced within the model, which again could lead to further insights.

\section{References}

Abdelkafi, N. and Täsucher, K. (2016) 'Business models for sustainability from a system dynamics perspective', Organization and Environment, Vol. 29, No. 1, pp.1-23.

Amit, R. and Zott, R. (2001) 'Value creation in e-business', Strategic Management Journal, Vol. 22, Nos. 6-7, pp.493-500.

Baines, T.S., Lightfoot, H., Steve, E., Neely, A., Greenough, R., Peppard, J., Roy, R., Shehab, E., Braganza, A., Tiwari, A., Alcock, J., Angus, J., Bastl, M., Cousens, A., Irving, P., Johnson, M., Kingston, J., Lockett, H., Martinez, V., Michelle, P., Tranfield, D., Walton, I. and Wilson, H. (2007) 'State-of-the-art in product-service systems', Journal of Engineering Manufacture, Vol. 221, No. 10, pp.1543-1552.

Baines, T.S., Lightfoot, H., Benedetti, O. and Kay, J. (2009) 'The servitization of manufacturing: a review of literature and reflection on future challenges', Journal of Manufacturing Technology Management, Vol. 20, No. 5, pp.547-567.

Banson, K.E. (2015) 'Consumer acceptance of irradiation for sterilization: a systemic approach to the case of medical items and food in Ghana', International Journal of Markets and Business Systems, Vol. 1, No. 1, pp.70-69.

Barlas, Y. (1996) 'Formal aspects of model validity and validation in system dynamics', System Dynamics Review, Vol. 12, No. 3, pp.183-210.

Bolivar-Ramos, M.T., Garcia-Morales, V.J. and Gracia-Sanchez, E. (2012) 'Technological distinctive competencies and organizational learning: effects on organizational innovation to improve firm performance', Journal of Engineering and Technology Management, Vol. 29, No. 3, pp.331-357.

Commitment for Steel (2016) Annual Report 2016 [online] http://www.stahl-online.de/wpcontent/ uploads/2016/11/WV-Stahl_Jahresbericht_2016-E-rz_Web.pdf (accessed 28 February 2017).

Dominici, G. (2012) 'Editorial note - Why does systems thinking matter?', Business Systems Review, Vol. 1, No. 1, pp.1-2.

Externbrink, K., Wilkens, U. and Lienert, A. (2013) 'Antecedents to the successful coordination of IPS $^{2}$ networks - a dynamic capability perspective on complex work systems in the engineering sector', in Shimomura, Y. and Kimita, K. (Eds.): The Philosopher's Stone for Sustainability, pp.103-108, Springer, Berlin/Heidelberg.

Federal Ministry for Economic Affairs and Energy (2015) Offshore wind energy - An overview of activities in Germany [online] http://www.bmwi.de/Redaktion/DE/Publikationen/Energie/ offshorewindenergie.pdf?_blob=publicationFile\&v=3. (accessed 28 February 2017).

Forrester, J. (1958) 'Industrial dynamics - a major breakthrough for decisions makers', Harvard Business Review, Vol. 36, No. 4, pp.37-66. 
Foundation Offshore Wind Energy (2016) Regional Policies for Offshore Wind: a Guidebook [online] http://www.offshorestiftung.de/sites/offshorelink.de/files/documents/ 2014_4POWER_Regional\%20Policies\%20for\%20Offshore\%20Wind_A\%20Guidebook_web version.pdf. (Accessed 28 February 2017)

Grandjean, L., Alevifard, S. and Steven, M. (2014) 'Strategic adaptability of industrial product-service systems - dynamic effective IPS ${ }^{2}$, Procedia CIRP, Vol. 16, pp.314-319.

Grandjean, L., Ries, E. and Steven, M. (2017) 'Geschäftsmodelltypologie für hybride Leisungsbündel', WiSt - Wirtschaftswissenschaftliches Studium, Vol. 46, Nos. 2-3, pp.17-23.

Kaiser, M.J. and Snyder, B.F. (2012) Offshore Wind Energy Cost Modeling - Installation and Decommissioning, Springer, London.

Kindström, D. (2010) 'Towards a service-based business model - key aspects for future competitive advantage', European Management Journal, Vol. 28, No. 6, pp.479-490.

Kurak, C., Barquet, A.P.B. and Rozenfeld, H. (2013) 'Challenges for PSS implementation: identification and classification', in Meier, H. (Ed.): Product-Service Integration for Sustainable Solutions, pp.275-285, Springer, Berlin/Heidelberg.

Lev, B. (2001) Intangibles, Brookings Institution Press, Washington, D.C.

Lieberman, M. (1987) 'The learning curve, diffusion, and competitive strategy', Strategic Management Journal, Vol. 8, No. 5, pp.441-452.

Mänz, K., Wilkens, U., Süße, T., and Lienert, A. (2013) 'Die Bewältigung hoher Arbeitsanforderungen in HLB, Mitarbeiterkompetenzen als ermöglichender Faktor in HLB-Arbeitsbereichen', wt werkstattstechnik online, Vol. 103, Nos. 7/8, pp.583-588.

Meier, H. and Bosslau, M. (2013) 'Design and engineering of dynamic business models for industrial product-service systems', in Shimomura, Y. and Kimita, K. (Eds.): the Philosopher's Stone for Sustainability, pp.179-184, Springer, Berlin/Heidelberg.

Meier, H. and Kortmann, D. (2007) 'Leadership - from technology to use - operation fields and solution approaches for the automation of service processes of industrial product-servicesystems', in Takata, S. and Umeda, Y. (Eds.): Advances in Life Cycle Engineering for Sustainable Manufacturing Businesses, pp.159-163, Springer, London.

Meier, H., Roy, R. and Seliger, G. (2010a) 'Industrial product-service systems-IPS ${ }^{2}$, , CIRP Annals - Manufacturing Technology, Vol. 59, No. 2, pp.607-627.

Meier, H., Uhlmann, E., Völker, O., Geisert, C. and Stelzer, C. (2010b) 'Reference architecture for dynamical organization of IPS $^{2}$ service supply chains in the delivery phase', 2nd CIRP Conference on Industrial Product-Service Systems, Linköping, Sweden.

Mont, O.K. (2002) 'Clarifying the concept of product-service system', Journal of Cleaner Production, Vol. 10, No. 3, pp.237-245.

Morecroft, J. (2015) Strategic Modelling and Business Dynamics - a Feedback Systems Approach, 2nd ed., John Wiley and Sons, West Sussex.

Nguyen, T.V., Nguyen, N.C. and Bosch, O.C.H. (2015) 'Contribution of the systems thinking approach to reduce production cost and improve the quality of Vietnamese coffee', International Journal of Markets and Business Systems, Vol. 1, No. 1, pp.53-69.

Oliva, R. and Kallenberg, R. (2003) 'Managing the transition from products to services', International Journal of Service Industry Management, Vol. 14, No. 2, pp.160-172.

Osterwalder, A. and Pigneur, Y. (2010) Business Model Generation, Campus, Frankfurt am Main, New York.

Porter, M. (1998) Competitive Advantage: Creating and Sustaining Superior Performance, 2nd ed., Free Press, New York.

Rese, M., Meier, H., Gesing, J. and Bosslau, M. (2013) 'An ontology of business models for industrial product-service systems', in Shimomura, Y. and Kimita, K. (Eds.): The Philosopher's Stone for Sustainability, pp.191-196, Springer, Berlin/Heidelberg. 
Richmond, B. (1993) 'System thinking: critical thinking skills for the 1990s and beyond', System Dynamics Review, Vol. 9, No. 2, pp.113-133.

Richmond, B. (2013) An Introduction in System Thinking [online] http://www.iseesystems.com/ resources/articles/download/intro-systemsthinking-chapt-1.pdf (accessed 22 November 2016).

Ries, E. (2016) Hybride Leistungsbündel in der Offshore-Windenergie Branche - Eine Betrachtung aus der Sicht von Unternehmen der deutschen Stahlindustrie [online] http://www.prowi.rub.de/mam/content/geschutzt/arbeitsbericht_nr15.pdf (accessed 15 December 2016).

Sterman, J. (2000) Business Dynamics - Systems Thinking and Modeling for a Complex World, Irwin/McGraw-Hill, Boston.

Steven, M. and Soth, T. (2010) 'Development accompanying calculation - How to calculate IPS ${ }^{2}$ costs during the early developement phase?', in Sakao, T., Larsson, T. and Lindahl, M. (Eds.): Industrial-Product-Service Systems (IPS ${ }^{2}$ ), pp.181-187, Springer, Berlin/Heidelberg.

Steven, M., Alevifard, S. and Keine genannt Schulte, J. (2011) 'Economic relevance of IPS ${ }^{2}$ flexibility', in Hesselbach, J. and Hermann, C. (Eds.): Functional Thinking for Value Creation, pp.261-265, Springer, Berlin/Heidelberg.

Storbacka, K. (2011) 'A solution business model: capabilities and management practices for integrated solutions', Industrial Marketing Management, Vol. 40, No. 5, pp.699-711.

Täuscher, K. and Chafac, M. (2016) 'Supporting business model decisions: a scenario based simulation approach', International Journal of Markets and Business Systems, Vol. 2, No. 1, pp.45-67.

Teece, D. (2000) Managing Intellectual Capital: Organizational, Strategic, and Policy Dimensions, Oxford University Press, New York.

Teece, D. (2010) 'Business models, business strategy and innovation', Long Range Planning, Vol. 43, Nos. 2-3, pp.172-194.

Thomsen, K. (2014) Offshore Wind - A Comprehensive Guide to Successful Offshore Wind Farm Installation, 2nd ed., Academic Press, Print on Demand, London.

Torres, J.P., Kunc, M. and O'Brien, F. (2017) 'Supporting strategy using system dynamics', European Journal of Operational Research, in press [online] http://www.sciencedirect.com/science/article/pii/S037722171730053X (accessed 28 February 2017).

Vandermerwe, S. and Rada, J. (1988) 'Servitization of business: adding value by adding services', European Management Journal, Vol. 6, No. 4, pp.314-324.

Wallin, J., Chirumalla, K. and Thompson, A. (2013) 'Developing PSS concepts from traditional product sales situation: the use of business model canvas', in Meier, H. (Ed): Product-Service Integration for Sustainable Solutions, pp.263-274, Springer, Berlin/Heidelberg.

Wewior, J., Alevifard, S., Kohl, H., Steven, M. and Seliger, G. (2014) 'Intellectual capital statement in IPS ${ }^{2}$, Procedia CIRP, Vol. 16, pp.301-307.

Windahl, C.H., Andersson, P., Berggren, C.H. and Nehler, C. (2004) 'Manufacturing firms and integrated solutions: characteristics and implications', European Journal of Innovation Management, Vol. 7, No. 3, pp.218-228.

Zott, C. and Amit, R. (2010) 'Business model design: an activity system perspective', Long Range Planning, Vol. 43, Nos. 2-3, pp.216-226. 